\section{Production of Penicillin}

THE usual method adopted in the large-scale production of penicillin is to grow Penicillium notatum on shallow layers of modified Czapek-Dox media ${ }^{1}$ at $24^{\circ} \mathrm{C}$. for 10-12 days. The metabolic solution at the end of the incubation period has an activity of 3-4 '0xford' units per c.c. This process involves handling large volumes of solution, and the space required is enormous. Moreover, the danger of contamination by penicillin-destroying bacteria during the lengthy incubation period is obvious.

Various attempts to shorten the incubation period and increase the yield of penicillin have been made; the more important ones are by Clifton ${ }^{2}$ and by Srinivasa $\mathrm{Rao}$ and $\mathrm{De}^{3}$. The first one suffers from the difficulty of bacterial contamination. The second method using semi-solid media has been developed further in our laboratories.

Among the various semi-solid media tried by us, the best so far was found to be wheat bran. It provides the necessary loose physical structure facilitating aeration and also provides a large surface for growth of the mould. Maximum anti-Staphylococcus aureus activity was reached after 48 hours incubation. Addition of nutrients like yeast extract, etc., did not increase the yield of penicillin or shorten the incubation period. The procedure is briefly as follows:

$30 \mathrm{gm}$. of wheat bran (particles of large size are preferable) are weighed out into 750 c.c. conical flasks, moistened with equal weight of water and mixed well. The flasks are plugged and autoclaved at $15 \mathrm{lb}$. pressure for one hour. The sterilized flasks are then inoculated with about 1 c.c. of a spore suspension of Penicillium notatum, well shaken and incubated at $24^{\circ} \mathrm{C}$. for two days. The flasks are shaken once after 24 hours. This procedure gave consistently penicillin activity of 30 'Oxford' units per gram with Fleming's strain (N.C.T.C. No. 4222) tested by serial dilution method against Staphylococcus aureus Oxford. Another strain of Penicillium notatum has given us an activity of 150 units per gram.

The advantages claimed for the above process apart from low cost of manufacture are: (1) ease of handling semi-solid media; (2) eonsistent yields'; (3) growth-time is reduced to two days, which is equivalent to increasing yield by five or six times; (4) the water extract of mouldy bran can be concentrated by using it for re-extraction with fresh mouldy bran to a fairly high potency; (5) bacterial destruction of penicillin is avoided; (6) large-scale methods used in the manufacture of taka-diastase can be used.

The concentrated crude extract is being used for local application to surface wounds with very good results.

My thanks are due to Drs. S. P. De and N. H. De for kind assistance and to Prof. V. Subrahmanyan for his keen interest in the work.

\section{S. Srinivasa Rao.}

Department of Biochemistry,

Indian Institute of Science, Bangalore.

April 6.

${ }^{1}$ Abraham, Chain, et al., Lancet, 241, 177 (1941).

' Clifton, C. E., Science, 98, 70 (1943).

- Srinivasa Rao, S., and De, S. P., Cur. Sci., 12, 209 (1943).

\section{Production of Ovulation by Fluoride in vitro}

IN the course of an investigation on the action of enzyme inhibitors on pituitary-induced ovulation of the frog's ovary (Rana pipiens) in vitro, it was found that sodium fluoride would potentiate the pituitary effect. This unexpected result was considered as possibly associated with the binding of calcium by fluoride. Accordingly, the effect of other experimental procedures such as the use of calcium-free Ringer, oxalate, change in $p \mathrm{H}$, etc., was investigated. A summary of the results together with probability values is shown in the accompanying table.

\begin{tabular}{|c|c|c|c|c|c|}
\hline Agent & $\begin{array}{l}\text { - Molar } \\
\text { cone. }\end{array}$ & $\begin{array}{l}\text { Pairs of } \\
\text { ovaries }\end{array}$ & \multicolumn{2}{|c|}{$\begin{array}{l}\text { No. eggs } \\
\text { extrudea }\end{array}$} & Value of $P$ \\
\hline & & & Treated & Control & \\
\hline with pituitary & $10^{-2}$ & 4 & 2159 & 634 & $<0.01$ \\
\hline $\begin{array}{l}\text { Sodium fluoride } \\
\text { without pituit- }\end{array}$ & & & & & \\
\hline $\begin{array}{l}\text { ary in calcium- } \\
\text { free Ringer }\end{array}$ & $10^{-2}$ & 16 & 1699 & & $<0.01$ \\
\hline Sodium oxalate & $10^{-2}$ & 12 & 3630 & 3974 & $<0.05$ \\
\hline Ringer & 一 & 8 & 1822 & 1031 & $0: 05-0.01$ \\
\hline $\begin{array}{l}\text { Ringer } p \mathrm{H} 5.6 \\
\text { (treated) and }\end{array}$ & & & & & \\
\hline $\begin{array}{l}p \mathrm{H} \\
\text { trol) }\end{array}$ & - & 8 & 672 & 2593 & $<0.01$ \\
\hline $\begin{array}{l}\text { Sodium iodo- } \\
\text { acetate }\end{array}$ & $10^{-8}$ & 4 & 0 & 1766 & 0.05 \\
\hline $\begin{array}{l}\text { Sodium iodo- } \\
\text { acetate }\end{array}$ & $9 \times 10^{-5}$ & 4 & 395 & 1366 & $0.05-0.01$ \\
\hline
\end{tabular}

The procedures were similar to those previously reported ${ }^{1}$. Unless otherwise specified, the ovaries were removed and suspended in a total volume of 30 c.c. of buffered Ringer $(p \mathrm{H} 7 \cdot 4)$ containing female frog pituitary together with the agent to be tested. Ovaries were studied in pairs, the left ovary serving as control for the right and vice versa. The total number of pituitary glands for the experiment was removed, finely macerated in 1-2 c.c. of distilled water, and taken up in a large volume of Ringer. The equivalent of two pituitary glands was then pipeted into a Petri dish into which one ovary was placed. Each experiment was allowed to run 31 hours, at the end of which time the ovaries were washed and the extruded eggs counted.

It is apparent (see table) that sodium fluoride potentiates the effect of pituitary in inducing ovulation and will, moreover, by itself cause egg release.

Fluoride may be considered to exert its action either through (1) a binding of calcium, or (2) an inhibition of some portion of the respiratory or glycolytic mechanisms. Chambers ${ }^{2}$ found that calcium is necessary for the stability of the intercellular cement of capillaries and kidney tubules; and when the calcium of the cement substance is decreased by using calcium-free solutions or lowering the $p \mathrm{H}$, it becomes loosened. Loosening of the intercellular cement could be expected to favour ovulation by permitting a more ready rupture of the cell layers surrounding the egg. While the results with fluoride and calcium-free Ringer might be interpreted on this basis, the oxalate and $p \mathrm{H}$ experiments apparently do not support such a view.

With respect to the action of fluoride on glycolysis, one may postulate that the accumulation or deficiency of a particular intermediate substance or substances initiates processes which result in ovulation. The relatively high concentration of fluoride $\left(10^{-2} \mathrm{M}\right)$ may well inhibit respiration as well as glycolysis. Inhibition 